To assess the effects of rituximab on immunoglobulin levels and incidence of infection among patients on rituximab

Methods: Data was collected of all $(\mathrm{N}=105)$ patients who received Rituximab between May 2014 until April 2015 at the Haywood Hospital where patients attend for Rituximab injections.

Data was collected retrospectively from the Diamond System, Medisec system and Clinical Information System and entered onto an excel spread sheet which included following details

- Start date of Rituximab

- IgG levels prior to Rituximab and current IgG levels

- Total doses of rituximab and frequency of IgG monitoring

- Intermittent infections and type of infections.

Results: We observed that 82 out of 105 patients were started on rituximab after February 2011 when the BSR guidance was published and 53 out of 105 patients had their immunoglobulin levels checked prior to commencing rituximab

$35 / 76(46 \%)$ patients had 1 or more episodes of infections whilst on Rituximab which required treatment. Of these, $16(46 \%)$ had recurrent infections.

39 patients had dropped their lgG levels after starting rituximab $18(46 \%)$ of these suffered from infections.

17 patients had a drop in $\lg G \geq 20 \%$ and 6 of these $(36 \%)$ had recurrent infections and 1 patient had 1 episode of infection.

None of the patients had dropped their lgG levels below 5

Conclusions: A significant number of patients $(35 / 76=46 \%)$ had 1 or more episodes of infections despite IgG levels being above lower normal limit

Among patients who dropped their lgG levels had increased number infections. Also they had more than 1 episodes of infection

Patients who dropped IgG levels $\geq 20 \%$ suffered with recurrent infections

References:

[1] BSR and BHPR guidelines on the use of rituximab in rheumatoid arthritis doi:10.1093/rheumatology/ker106b.

Disclosure of Interest: None declared

DOI: 10.1136/annrheumdis-2017-eular.1160

\section{AB0400 EFFICACY AND SAFETY OF INTRAVENOUS AND SUBCUTANEOUS TOCILIZUMAB IN A COHORT OF PATIENTS AFFECTED BY RHEUMATOID ARTHRITIS IN REAL-LIFE}

G. Pomponio, C. Tontini, A. Angeletti, D. Olivari, D. Benfaremo, L. Manfredi, M.G. Danieli, P. Fraticelli, M.M. Luchetti, G. Moroncini, A. Gabrielli. Department of Internal Medicine, Azienda Ospedaliero-universitaria 'Ospedali Riuniti', Ancona, Italy

Background: Tocilizumab (TCZ) is a humanized monoclonal anti-interleukin- 6 receptor antibody, used for the treatment of moderate to severe rheumatoid arthritis (RA). Although TCZ has been proved to be highly effective and safe in RA patients in large clinical trials, few data are available from real-life practice [1]. Objectives: To evaluate efficacy, safety and retention rate of intravenous (IV) and subcutaneous (SC) TCZ in a real-world setting.

Methods: We evaluated patients affected by moderate-to-severe RA and treated with TCZ from April 2010 to January 2017. Data of patients treated with IV-TCZ until January 2017 were collected retrospectively, while patients treated with either IV or SC-TCZ from January 2015 were included in a prospective cohort and assessed for disease activity, treatment discontinuation and/or onset of adverse events (AEs). DAS28-CRP, CDAI and SDAI scores were used for disease activity assessment and paired $t$ test was used for statistical analysis. Treatment retention rate was estimated by Kaplan-Meier method.

Results: We evaluated 100 patients, 58 treated with IV-TCZ (8 mg/kg every $4 \mathrm{w}), 16$ with SC-TCZ (162 mg every week), 26 switched from IV to SC during followup and 6 of these returned to IV-TCZ for cutaneous intolerance ( 80 females, median age $63 \mathrm{y}$, median duration of disease $11 \mathrm{y}$, median follow-up 16 months). Seventy-eight patients (78\%) were treated with monotherapy and twenty-two $(22 \%)$ in combination with methotrexate. At baseline, disease activity was severe in $87 \%$ of patients, moderate in $6 \%$ and mild or inactive in $7 \%$; at the latest follow-up $60 \%$ of patients are in clinical remission. The mean DAS28-CRP in IV-TCZ and SW-TCZ groups considered as a whole was 4.34 at baseline and 2.71 at the latest follow-up available $(p<0.0001)$. In the SC-TCZ group, mean basal DAS28-CRP was 3.70 vs 1.89 measured at the latest follow-up $(p<0.0001)$. Fiftythree patients $(53 \%)$ discontinued TCZ because of inefficacy (19), AEs (13) or other reasons (21, mostly lost to follow-up). Infections were the most frequent $A E$ (45.1/100 person-years), 3 cases of severe pneumonia, one required treatment discontinuation. Infusion reactions were reported in 6/58 IV-TCZ patients, while injection site reactions in 14/42 SC-TCZ patients. Six of these intolerant patients were subsequently treated with i.v. tocilizumab without reactions. We observed an overall high retention rate of IV-TCZ and SW-TCZ $(91.1 \%, 81.2 \%, 70.6 \%, 61.3 \%$, $57.1 \%$ and $50 \%$ at $1,2,3,4,5$, and 6 years respectively). The retention rate of SC-TCZ patients at 3 years was about $77 \%$. The difference between IV/SW-TCZ and SC-TCZ groups was not significant (Fig. 2)

Conclusions: TCZ is effective, well tolerated and safe in a population of RA patients followed in a real-life setting.

No unexpected $A E$ was observed in this large population followed for a long period. Interestingly retention rate was not affected by the administration route and in real life many patients can safely shift across different administration modalities.
References:

[1] Gabay C, Riek M, Hetland ML, Hauge EM, Pavelka K, Tomšič M, et al. Effectiveness of tocilizumab with and without synthetic disease-modifying antirheumatic drugs in rheumatoid arthritis: results from a European collaborative study. Ann Rheum Dis. 2015 Sep 15

Disclosure of Interest: None declared

DOI: 10.1136/annrheumdis-2017-eular.6724

\section{AB0401 THE EFFICENT REGULATION OF TOCILIZUMAB FOR THE EXPRESSION OF CD4+/CD8+ T/CD19 + B CELLS AND THE IMMUNOGLOBULIN IN SYSTEMIC JUVENILE IDIOPATHIC ARTHRITIS}

H. Li ${ }^{1}, \mathrm{H}$. Zeng ${ }^{2} .{ }^{1}$ Department of Pediatric Allergy, Immunology and Rheumatolog; ${ }^{2}$ Department of Pediatric Allergy, Immunology and Rheumatology, Guangzhou Women and Children's Medical Center, Guangzhou, China

Objectives: To study the influence of tocilizumab on lymphocyte subsets, immunoglobulin and biochemical indicators of Systemic juvenile idiopathic arthritis. Methods: DMARDs poor efficacy in children with severe SJIA 18 patients were divided into two groups, of which eight patients tocilizumab + DMARDs group (in cluding a case of refractory MAS), 10 patients in the placebo + DMARDs control group, according to the weight $>30 \mathrm{~kg}, 8 \mathrm{mg} / \mathrm{kg},<30 \mathrm{~kg}, 12 \mathrm{mg} / \mathrm{kg}$, injected once every two weeks in hospital.Symptoms and CD3 +, CD4 +, CD8 + T, CD19 + B, CD16 + 56-NK cell ratio in two groups were observed by the flow cytometry before or after 12 weeks treatment. Comparing immunoglobulin $\lg G, \lg \mathrm{M}, \lg \mathrm{A}$, $\lg \mathrm{E}$ with baseline after the therepy in two group, and continuous observe inflammatory markers (CRP, ESR, FER, WBC) and ALT/AST changes, adverse reactions and reduce stopping hormone case inductive analysis in following 12 weeks.

Results: After 12 weeks, tocilizumab + DMARDs group, CRP, ESR, FER were significantly decreased, the most frequently occurring adverse reaction was infection, mostly upper respiratory tract infection, followed by elevated transaminase, cholesterol, low-density lipoprotein High-density lipoprotein and triglyceride levels increased; two groups no serious adverse events (three-line reduction, severe infections, etc.). the proportion of CD4 + T, CD19 + B cells in Tocilizumab group were lower than baseline $(P<0.05), C D 8, C D 3+T$ cells were increased in comparing with baseline, however,no significant change with CD16 +56 -NK cells $(P>0.05)$, and immunoglobulins IgG, IgM, IgA lower than baseline $(P<0.05)$. The control group had no significant difference $(P>0.05)$.

Conclusions: Tocilizumab can significantly reduce inflammatory markers (CRP, ESR, FER), but affect lipid metabolism and ALT/AST.Blocking IL-6 can be adjusted hyperthyroidism humoral and regulate CD4 + T, CD19+B cells, reduce joint destruction. Tocilizumab can effectively control the development of DMARDs poor efficacy SJIA.

Disclosure of Interest: None declared

DOI: 10.1136/annrheumdis-2017-eular.2114

\section{AB0402 RITUXIMAB MAY DELAY THE MOVEMENT OF RHEUMATOID ARTHRITIS PATIENTS ON CARDIORENAL CONTINUUM: RESULTS FROM A PROSPECTIVE OBSERVATIONAL SINGLE-CENTRE COHORT STUDY}

I.R. Gaisin ${ }^{1}$, L.V. Ivanova ${ }^{2}$, A.A. Trukchina ${ }^{2}$, A.A. Tukmacheva ${ }^{2}$, Y.A. Volkova ${ }^{1}$, A.A. Tebenkova ${ }^{1}$, N.I. Maximov ${ }^{1} .{ }^{1}$ Izhevsk State Medical Academy; ${ }^{2}$ Clinical Diagnostic Centre of the Udmurt Republic, Izhevsk, Russian Federation

Background: Similarities in risk factors, initial stages, progression and final stage of both atherosclerotic cardiovascular disease (CVD) and chronic kidney disease (CKD) allowed formulating a concept of cardiorenal continuum. ${ }^{1}$ CVD and CKD remain the main causes of mortality in rheumatoid arthritis (RA) patients. ${ }^{2,3}$

Objectives: We aimed to evaluate the effects of rituximab biologic therapy on cardiorenal continuum of RA patients.

Methods: Biologics-naïve RA patients ( $n=50$; age $55.1 \pm 10.3$ ) were followed up for 72 months after commencing and continuing rituximab therapy (1-10 standard courses) compared with 30 control RA patients (age 53.2 \pm 9.8 ).

Results: At year 6, rituximab patients have fewer incidences of hypertension, anxiety/depression, atherosclerosis and diastolic dysfunction than control patients (Table).

There were no significant differences in frequencies of other risk factors, signs of asymptomatic multiorgan damage and cases of established heart, cerebrovascular and renal diseases/complications.

Conclusions: Rituximab may be effective in delay of the movement of RA patients on cardiorenal continuum. The clinical implications of rituximab for cardiorenal correlations in RA patients need to be confirmed in large-scale clinical outcome trials.

References:

[1] Sarnak MJ, Levey AS. Cardiovascular disease and chronic renal disease: a new paradigm. Am J Kidney Dis 2000;35(4, Suppl. 1):117-31.

[2] Avina-Zubieta JA, Choi HK, Sadatsafarvi M, et al. Risk of cardiovascular mortality in patients with rheumatoid arthritis: a meta-analysis of observational studies. Arthritis Rheum 2008:59:1690-7.

[3] Gullick NJ, Scott DL. Co-morbidities in established rheumatoid arthritis. Best Pract Res Clin Rheumatol 2011;25:469-83. 
Abstract AB0402 - Table 1. Cardiorenal continuum features of rheumatoid arthritis patients (\%)

\begin{tabular}{|c|c|c|c|c|c|c|c|c|}
\hline & \multirow[t]{2}{*}{ Features } & \multicolumn{3}{|c|}{ Rituximab group } & \multicolumn{3}{|c|}{ Control group } & \multirow[t]{2}{*}{$\mathrm{P}_{\mathrm{R}-\mathrm{C}}$} \\
\hline & & 1 year, $n=50$ & 3 years, $n=47$ & 6 years, $n=31$ & 1 year, $n=30$ & 3 years, $n=26$ & 6 years, $n=16$ & \\
\hline \multirow[t]{7}{*}{ Risk factors } & Hypertension & 50.0 & 38.3 & $\begin{array}{c}25.8 \\
\mathrm{p}_{6-1}=0.028\end{array}$ & 40.0 & 38.5 & 50.0 & $\mathrm{p}_{6}=0.032$ \\
\hline & Dyslipidaemia & 44.0 & 36.2 & 38.7 & 40.0 & 46.2 & 50.0 & $>0.05$ \\
\hline & Pre-diabetes & 52.0 & 36.2 & 41.9 & 33.3 & 34.6 & 56.3 & $>0.05$ \\
\hline & Metabolic syndrome & 12.0 & 6.4 & 3.2 & 10.0 & 7.7 & 12.5 & $>0.05$ \\
\hline & Diabetes mellitus & 4.0 & 0 & 0 & 0 & 0 & 0 & $>0.05$ \\
\hline & Anxiety/depression & 83.2 & 41.5 & 35.3 & 80.0 & 73.1 & 68.8 & $\mathrm{p}_{3}=0.009$ \\
\hline & & & $\mathrm{p}_{3-1}=0.006$ & $\mathrm{p}_{6-1}<0.001$ & & & & $p_{6}=0.008$ \\
\hline \multirow[t]{7}{*}{ Initial stages } & Atherosclerosis & 32.0 & 21.3 & 12.9 & 40.0 & 34.6 & 37.5 & $p_{6}=0.02$ \\
\hline & & & & $p_{6-1}=0.048$ & & & & \\
\hline & Left ventricular hypertrophy & 8.0 & 4.3 & 0 & 6.7 & 7.7 & 0 & $>0.05$ \\
\hline & Diastolic dysfunction & 48.0 & 38.3 & 22.6 & 46.7 & 50.0 & 56.3 & $\mathrm{p}_{6}=0.04$ \\
\hline & & & & $p_{6-1}=0.022$ & & & & \\
\hline & Albuminuria & 8.0 & 0 & 0 & 0 & 0 & 6.3 & $>0.05$ \\
\hline & Kidney impairment & 6.0 & 2.1 & 0 & 13.3 & 0 & 0 & $>0.05$ \\
\hline \multirow[t]{2}{*}{ Progression } & Angina & 6.0 & 0 & 0 & 3.3 & 0 & 0 & $>0.05$ \\
\hline & Chronic kidney disease & 16.0 & 8.5 & 9.7 & 13.4 & 0 & 0 & $>0.05$ \\
\hline \multirow[t]{4}{*}{ End stage } & Myocardial infarction/stroke & 0 & 0 & 0 & 0 & 0 & 0 & $>0.05$ \\
\hline & Heart failure & 2.0 & 0 & 0 & 0 & 0 & 0 & $>0.05$ \\
\hline & Acute/chronic renal failure & 0 & 0 & 0 & 0 & 0 & 0 & $>0.05$ \\
\hline & Death & 0 & 0 & 12.9 & 0 & 0 & 0 & $>0.05$ \\
\hline
\end{tabular}

Disclosure of Interest: None declared

DOI: 10.1136/annrheumdis-2017-eular.5704

\section{AB0403 ADHERENCE AND ACCESS TO BIOLOGICAL THERAPY AND TOFACITINIB IN A COHORT OF COLOMBIAN PATIENTS WITH RHEUMATOLOGICAL DISEASES}

J.E. Machado-Alba, M.E. Machado-Duque, S. Granada on behalf of Grupo de Investigación en Farmacoepidemiología y Farmacovigilancia, Universidad Tecnológica de Pereira-Audifarma S.A, Pereira, Colombia. Grupo de Investigación en Farmacoepidemiología y Farmacovigilancia, Universidad Tecnológica de Pereira-Audifarma S.A, Pereira, Colombia

Background: Biological disease-modifying antirheumatic drug (bDMARD) and tofacitinib are highly effective, but with different pharmaceutical forms, adverse reactions and cost that could affect adherence therapy and drug access.

Objectives: To determine patient adherence and administrative access to the treatment with bDMARDs and tofacitnib in patients with rheumatological diseases in Colombia.

Methods: A retrospective cohort study, which included all patients in management with bDMARD and tofactinib initiated between July 1, 2015 and June 30, 2016. A monthly follow-up of the administrative adherence were evaluated by holding or applying the medication, as well as the application of Morisky-Green test in self-administered oral and subcutaneous therapies (non-adherent patient was considered when at least one doses is lost), other variables such as sociodemographic, comorbidities, and co-prescriptions were evaluated. A descriptive analysis, $\chi^{2}$ for comparison and multivariate logistic regression were performed. Results: A total of 1102 patients were evaluated, with a mean age of $52.8 \pm 15.4$ years and a female predominance $(72.8 \%)$. The most frequent comorbidities were hypertension (22.6\%) and dyslipidemia (15.9\%). The most prescribed drugs studied were adalimumab $(31.9 \%)$, etanercept $(22.2 \%)$ and tofacitinib (12.5\%). 52.8\% use conventional DMARDs and $42.2 \%$ use glucocorticoids. Global adherence was $66.3 \%$ as measured by Morisky-Green test. Adherence was better with self-administered subcutaneous drugs every week or longer, compared to daily dosing of oral drug; these data are detailed in table 1. In $42.4 \%$ of the patients, at least one delay per year in the application or dispensation occurred, leading to $36.1 \%$ of patients experiencing dose losses due to difficulties in access. The main reason (23\%) for delays and dose losses is the failures by health-insurance companies to allow timely access to the therapy. In the multivariate analysis treatment with adalimumab or tofacitinib was associated with a greater probability of presenting delays in access after adjustment of variables.

\begin{tabular}{|c|c|c|c|c|c|c|}
\hline Drug & (n) & (\%) & $\begin{array}{l}\text { Drug administration route and } \\
\text { interval }\end{array}$ & $\begin{array}{c}\text { Morisky-Green } \\
\text { test adherence } \\
\text { (\%) }\end{array}$ & $\begin{array}{l}\text { At least one dose } \\
\text { application delay in the } \\
\text { year of follow up (\%) }\end{array}$ & $\begin{array}{l}\text { Missed } \\
\text { dose (\%) }\end{array}$ \\
\hline Adalimumab & 351 & 31.9 & SC-Every two weeks & 74.8 & 62.7 & 51.3 \\
\hline Etanercept & 245 & 22.2 & SC-weekly & 72 & 27.3 & 22.4 \\
\hline Tofacitinib & 138 & 12.5 & $\mathrm{OA}$ - every 12 hours & 48.8 & 52.2 & 52.2 \\
\hline Golimumab & 82 & 7.4 & SC- monthly & 64.7 & 32.9 & 28 \\
\hline Rituximab & 66 & 6.0 & IV - biannual and annual & Not apply & 3.0 & 1.5 \\
\hline Certolizumab & 58 & 5.3 & SC - monthly & 83.3 & 32.8 & 32.8 \\
\hline Infliximab & 40 & 3.6 & IV - monthly and every two months & Not apply & 35.0 & 27.5 \\
\hline Abotacept & 62 & 5.6 & IV y SC- monthly and weekly & 42.9 - (SC route) & 38.7 & 27.4 \\
\hline Tocilizumab & 60 & 5.4 & IV y SC-monthly & $50.0 \cdot$ (SC route) & 36.7 & 33.3 \\
\hline
\end{tabular}

Conclusions: Subcutaneous self-applications of bDMARD have better adherence rates compared to oral drug. However, the limitations in access to treatment decrease the adherence. On the other hand the impact of the adherence could be major in the case of self-administered DMARD when weekly or longer intervals doses are lost, compared with the loss of one daily dose of tofacitinib.
References:

[1] Scott DL, et al. Rheumatoid arthritis. Lancet. 2010;376(9746):1094-108.

[2] Machado-Alba JE, et al. Effectiveness of treatment with biologic- and DMARD in rheumatoid arthritis patients in Colombia. Int J Clin Pract. 2016;70(6):50611.

[3] Jorgensen TS, et al. Effectiveness and drug adherence of biologic monotherapy in routine care of patients with rheumatoid arthritis: a cohort study of patients registered in the Danish biologics registry. Rheumatology. 2015;54(12):215665.

Acknowledgements: To Universidad Tecnológica de Pereira and Audifarma S.A Disclosure of Interest: J. Machado-Alba Grant/research support from: The authors declare that Pfizer Colombia financed the data collection process in medical records. There was no intervention in the stages of processing, analysis or publication of that data. No non-financial conflicts of interest exist for any of the authors., M. Machado-Duque: None declared, S. Granada: None declared DOI: 10.1136/annrheumdis-2017-eular.5263

\section{AB0404 SIMILAR REMISSION RATES AMONG RHEUMATOID ARTHRITIS PATIENTS TREATED WITH ANTI TNF AND NON-ANTI TNF THERAPIES: REAL-LIFE DATA}

J.A. Gómez-Puerta ${ }^{1,2}$, N. Duque ${ }^{1}$, M. Saldarriaga ${ }^{1}$, L.A. González ${ }^{1,2}$, C. Cerón ${ }^{1}$, L. Uribe Botero ${ }^{1}$, O.J. Felipe-Díaz ${ }^{1}$. ${ }^{1}$ Medicarte IPS; ${ }^{2}$ Grupo de Reumatología, Universidad de Antioquia, Medellín, Colombia

Background: Several biological DMARD (bDMARD) therapies have been approved for use in rheumatoid arthritis (RA) and are classified according to their respective therapeutic target: Anti TNF therapies and non-Anti TNF therapies. They are very effective in most of patients but their comparative efficacy in daily clinical is less well known.

Objectives: Our aim was to compare the efficacy of anti-TNF therapies vs non-Anti TNF therapies in a cohort of Colombian RA patients followed in different arthritis clinics under daily clinical practice conditions.

Methods: We conducted a cross-sectional study including with RA patients treated at Medicarte IPS from March 2009 to December 2016. Medicarte is a referral center for the integral medical care and pharmaco-surveillance of patients under biologic therapies in 13 cities in Colombia for inflammatory arthropathies, mainly RA, psoriatic arthritis and spondyloartropathies. Clinical information was obtained from electronic clinical records and medical claims. Only those patients with disease activity scores (DAS-28) at baseline and at the last visit were included. Remission was defined as DAS-28 $<2.6$ on the last visit. Patients treated only with conventional DMARD and/or tofacitinib were excluded.

Results: A total of 1,020 patients with RA were identified. 844 patients $(88 \%$ female) were included in the final analysis, 416 patients with anti TNF and 428 with non-anti TNF therapies (Rituximab 199, Tocilizumab 125 and Abatacept in 104 patients). The mean age was $55.2 \pm 11.8$ years, with a mean disease duration

Table 1. General Characteristics of patients with RA under bDMARD therapy

\begin{tabular}{lcccc}
\hline & $\begin{array}{c}\text { Total } \\
\mathrm{N}=844\end{array}$ & $\begin{array}{c}\text { Anti TNF } \\
\mathrm{N}=416\end{array}$ & $\begin{array}{c}\text { Non-Anti TNF } \\
\mathrm{N}=428\end{array}$ & $\mathrm{p}$ value \\
\hline Gender (female) \% & 88.0 & 88.7 & 87.6 & $\mathrm{NS}$ \\
Age (years, SD) & $55.2 \pm 11.8$ & $55.0 \pm 11.8$ & $55.4 \pm 11.8$ & $\mathrm{NS}$ \\
Disease duration (years, SD) & $15.2 \pm 9.5$ & $15.0 \pm 9.9$ & $15.5 \pm 9.0$ & $\mathrm{NS}$ \\
bDMARD therapy duration (years) & $3.2 \pm 2.5$ & $3.2 \pm 2.5$ & $3.2 \pm 2.4$ & $\mathrm{NS}$ \\
First line bDMARD therapy,\% & 64.0 & 75.2 & 53.2 & $\mathrm{p}<0.001$ \\
Combined therapy, \% & 83.0 & 90.9 & 75.0 & $\mathrm{p}<0.001$ \\
Seropositive (either CCP and/or RF) \% & 80.1 & 82.0 & 78.3 & $\mathrm{NS}$ \\
DAS-28 at baseline $( \pm \mathrm{SD})$ & $4.3 \pm 1.1$ & $4.20 \pm 1.14$ & $4.4 \pm 1.21$ & $\mathrm{NS}$ \\
HAQ at baseline $( \pm \mathrm{SD})$ & $1.13 \pm 0.77$ & $1.09 \pm 0.78$ & $1.16 \pm 0.77$ & $\mathrm{NS}$ \\
\hline
\end{tabular}

